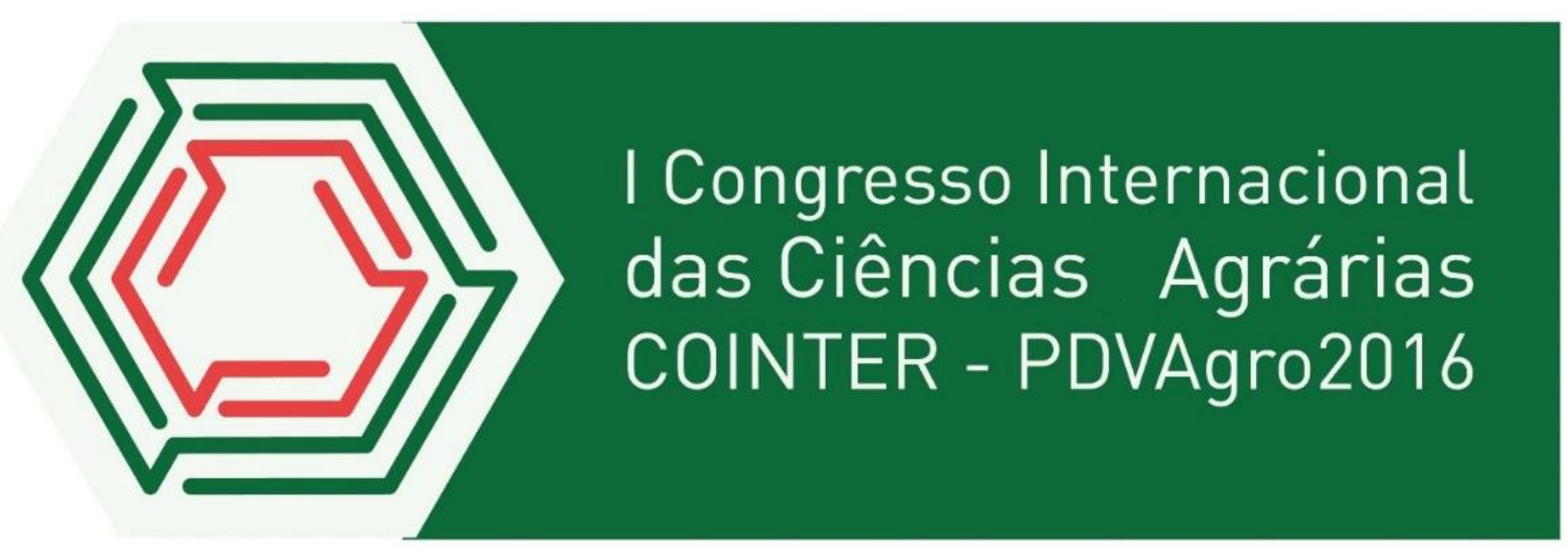

\title{
CARACTERIZAÇÃO FÍSICO-QUÍMICA DA POLPA DA SEMENTE DO JATOBÁ (Hymenaea Courbaril L.) CULTIVADO NO AGRESTE PERNAMBUCANO \\ Apresentação: Comunicação Oral
}

\author{
Venancio Ferreira de Moraes Neto ${ }^{1}$; Renato Henrique Florêncio Teixeira ${ }^{1}$; Anyelle Mikaelle Pereira \\ Veloso $^{1}$; Suzana Pedroza da Silva ${ }^{2}$ \\ ${ }^{1}$ Estudante do Curso de Engenharia de Alimentos - UAG - UFRPE; \\ E-mail: venanciomoraes@ hotmail.com, \\ ${ }^{2}$ Docente da UAG - UFRPE. E-mail: suzpedroza@gmail.com
}

\section{Resumo}

O jatobá (Hymenaea Courbaril L.) pode ser consumido in natura ou como ingrediente alimentício por apresentarem atividades antioxidantes, ricos nutricionalmente contendo compostos funcionais, tais como, carotenóides, polifenóis, vitamina $\mathrm{C}$, sais minerais, fibras e ácidos graxos essenciais. $\mathrm{O}$ fruto é muito apreciado pela população do agreste pernambucano, porém ainda subutilizado na alimentação, por exemplo, como farináceo. As características físico-químicas dos alimentos são essenciais para avaliação do consumo e formulação de novos produtos, além das características sensoriais. O objetivo deste trabalho foi caracterizar fisico-quimicamente a polpa do jatobá cultivado no agreste pernambucano para dar início a trabalhos de incentivo de consumo pela população deste fruto em seu cotidiano. Os frutos foram coletados entre julho e agosto de 2016 no município de Jucati-PE, lavados e despolpados. Determinou-se a umidade por meio da secagem em estufa a $105^{\circ} \mathrm{C}$ por $4 \mathrm{~h}$; cinzas em mufla a $550^{\circ} \mathrm{C}$, expressos os teores de minerais em percentagem (\%); acidez total titulável em g/100g de ácido cítrico, sólidos solúveis totais ( ${ }^{\circ}$ Brix) em refratômetro e; $\mathrm{pH}$ com pHmetro. As análises foram realizadas em triplicata seguindo metodologias do Instituto Adolfo Lutz. A polpa de jatobá apresentou 22,6 $\pm 2,50 \%$ de umidade, teor de cinzas de 2,44 \pm $0,045 \%$, acidez de $1,55 \pm 0,25 \mathrm{~g} / 100 \mathrm{~g}$ de ácido cítrico, confirmando seu sabor adstringente com um valor de $\mathrm{pH}$ de $5,45 \pm 0,02$ e 3,9 $\pm 0,08^{\circ}$ Brix. O clima e o manejo são determinantes à composição dos alimentos o que pode ter influenciado nas variações dos valores encontrados em relação aos encontrados na literatura. Ainda assim, pode-se considerar a utilização da polpa do jatobá cultivado no agreste pernambucano na elaboração ou enriquecimento de outros alimentos.

Palavras-Chave: Perfil nutricional, Frutos nativos, Complementação alimentar.

\section{Introdução}

A fruticultura no Nordeste brasileiro constitui-se em atividade econômica bastante promissora, devido ao sabor e aroma exótico de seus frutos e à sua enorme diversificação. Apesar de muitas frutíferas apresentarem amplas perspectivas de aproveitamento econômico, poucas, como 
jatobazeira, cajazeira, umbuzeiro e umbu-cajazeira, têm sido exploradas, na maioria das vezes de forma extrativista, dada a falta de informações que possibilitem sua exploração comercial. (SANTOS et al. 2010).

O jatobá, Hymenaea Courbaril L., é um fruto comestível que apresenta uma polpa farinácea com coloração geralmente branca ou amarelada, alto teor de fibras e comumente apreciada pela população do agreste de Pernambuco. O consumo do fruto pode ser realizado in natura ou usado como igrediente para elaboração de outros produtos alimentícios. A árvore que dá seu fruto tem de 4 a 6 metros de altura, sendo mais encontrada na Amazônia e na Mata Atlântica brasileira. O fruto é uma vagem indeiscente (não se abre quando maduro), lenhosa, glabra (sem pelos), oblongo (mais comprido que largo) a cilíndrica, que mede $8-15 \mathrm{~cm}$ de comprimento; o exocarpo é espesso e vermelho-escuro; o endocarpo é farináceo, adocicado, amarelo-claro e mucilaginosa. As sementes, em número de 2 a 6 por fruto ou mais, apresentam formato obovóide (com o ápice mais largo do que a base) a elipsóide (MELO \& MENDES, 2005).

As características físico-químicas dos alimentos, entre elas teor de cinzas, umidade, sólidos solúveis totais, acidez e pH são essenciais para avaliação do consumo e formulação de novos produtos (SOUSA, 2012). Logo, o objetivo desse trabalho foi determinar as características físicoquímicas da polpa da semente do jatobá cultivado no agreste de Pernambuco a fim de incentivar a população local um maior aproveitamento do fruto enriquecendo sua alimentação diária.

\section{Fundamentação Teórica}

Segundo Matuda e Maria Netto (2005), o jatobá é uma leguminosa característica brasileira, é uma planta com 4 a $6 \mathrm{~m}$ de altura que produz frutos (Figura 1) com comprimento entre 6 e $18 \mathrm{~cm}$ e diâmetro de 3 a 6 cm. De acordo com Guarim Neto (1997), o jatobá é considerado uma planta medicinal, tradicionalmente utilizada na Amazônia brasileira. Para alguns povos indígenas sua utilização é historicamente cultural. Sementes leguminosas como o Jatobá têm sido estudadas para a utilização na alimentação humana. Sua utilização na alimentação humana se deve as suas propriedades, como: ação adstringente, antibacteriana, antiespasmódica, antifúngica, antiinflamatória, antioxidante, balsâmica, descongestionante, diurética, estimulante, expectorante, fortificante, hepatoprotetora, laxante, tônica e vermífuga. Cohen (2010) afirma que o fruto apresenta significativo valor nutricional e contêm compostos funcionais, como carotenóides, vitamina C, polifenóis, fibras, sais minerais e ácidos graxos essenciais. Estudos da composição das farinhas de jatobá-do-cerrado e jatobá-da-mata revelaram que os teores de nutrientes apresentam diferenças marcantes quando comparados com a composição de outras leguminosas (TEIXEIRA e SANTOS, 2007). 
Segundo Brasil (1999) o fruto é composto por sementes (25\% a 40\% do peso), vagem (50\% a $70 \%$ ) e polpa (apenas 5\% a 10\%). O valor proteico da farinha de jatobá é semelhante ao do fubá de milho e superior ao da farinha de mandioca. Cem gramas do fruto fornecem 115 calorias, 29,4 gramas de glicídios e 33 miligramas de vitamina $\mathrm{C}$.

Figura 1- Fruto do Jatobá in natura

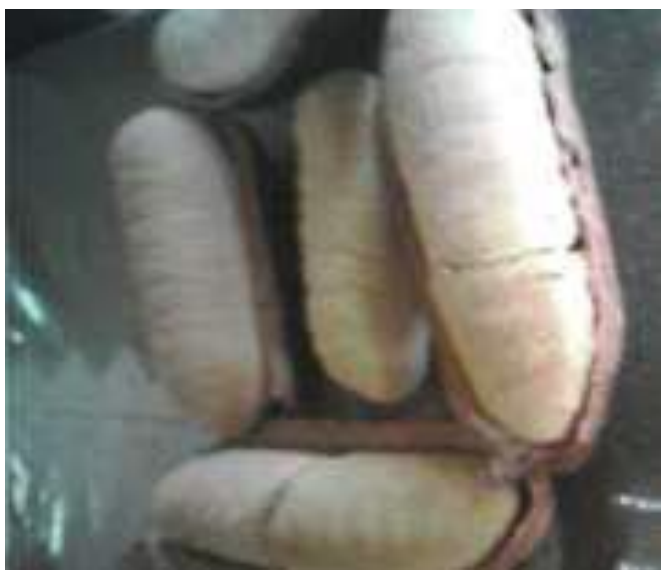

Fonte: Sousa, et al. (2012)

A produção de alimentos gera grande impacto em qualquer economia e isso pode ser devido a sua abrangência e essencialidade. Geralmente as empresas produzem e vendem tanto alimentos do tipo commodity com baixo valor agregado, quanto os processados que incorporam maior tecnologia (GOUVEIA, 2006).

Segundo Santos et al., (2001) a alimentação alternativa é uma proposta de promover na dieta brasileira o uso de alimentos tradicionais e não tradicionais ricos em vitaminas e minerais, que são acessíveis a toda população.

O conhecimento de algumas características físicas e físico-químicas de frutos são indispensáveis para a determinação do estádio de amadurecimento mais adequado para a colheita desses produtos. As características físico-químicas dos alimentos também podem influenciar a sua utilização como ingrediente em produtos para alimentação humana, com possiblidade da polpa de jatobá ser utilizada em produtos de panificação, os quais são bem aceitos por essa população, além de conferir novas características tecnológicas, nutricionais e sensoriais (SILVA et al., 2012). Segundo Silva (2001), alguns estudos demonstraram que a farinha de jatobá-do-cerrado possui elevado conteúdo de fibra alimentar total, com grande potencial para utilização na preparação de produtos como "cookies" e "snacks".

A análise de alimentos é essencial no segmento alimentício, pois ela atua em várias etapas do controle de qualidade, do processamento e do armazenamento dos alimentos processados. Nas análises de alimentos, os objetivos se resumem em determinar um componente específico do 
alimento, ou vários componentes, como no caso da determinação da composição centesimal (SILVA, 2010).

\section{Metodologia}

Os frutos foram coletados entre julho e agosto de 2016 no município de Jucati-PE e transportados para o Laboratório de Química da Unidade Acadêmica de Garanhuns na Universidade Federal Rural de Pernambuco, onde foram selecionados de acordo com tamanho e grau de maturação, lavados, retiradas as cascas com martelo de aço inox e feita a remoção da polpa para análises.

Todas as análises foram realizadas em triplicata de acordo com as metodologias propostas pelo Instituto Adolfo Lutz (INSTITUTO ADOLFO LUTZ, 2008). Os parâmetros avaliados foram: umidade; teor de cinzas; acidez total titulável; sólidos solúveis totais e pH.

A umidade foi determinada a partir do método gravimétrico, calculando-se a diferença entre a amostra seca em estufa em relação à amostra inicial. A secagem foi feita em estufa (MARQLABOR, MAQEES42) a $105^{\circ} \mathrm{C}$. As pesagens foram feitas em balança analítica (SHIMADZU, AY220, precisão de 0,0001 g). A primeira pesagem foi feita a partir de $2 \mathrm{~g}$ da amostra após $4 \mathrm{~h}$ de secagem. Posteriormente foi levada ao dessecador até a temperatura ambiente para pesagem. O procedimento foi repetido até que o peso da amostra permanecesse constante. $\mathrm{O}$ peso da amostra seca foi subtraído do peso antes da secagem e o teor de água foi expresso em porcentagem de água (\%). Foram necessárias 4 horas para perda total da umidade.

Para determinação do teor de cinzas aqueceram-se três cadinhos de porcelana a $550^{\circ} \mathrm{C}$ por 30 minutos em forno mufla (ZEZIMAQ, 2000), sendo resfriados em dessecador e pesados. Pesou-se $2 \mathrm{~g}$ da amostra nos cadinhos previamente limpos, secos e em temperatura ambiente, que em seguida foi submetida à incineração em mufla a $550^{\circ} \mathrm{C}$. Foram necessárias 3 horas para obtenção total das cinzas. O resultado foi expresso em teor de minerais em porcentagem (\%). A partir da equação 1: \% cinzas $=\left(100 . \mathrm{m}_{1}\right) / \mathrm{m}_{2}$, determinou-se a porcentagem de cinzas do extrato da polpa da semente do jatobá.

\footnotetext{
Em que:

$\mathrm{m}_{1}=$ massa da amostra após incineração (cinzas);

$\mathrm{m}_{2}=$ massa da amostra, em gramas.
}

Para a análise de sólidos solúveis totais (SST) foi pipetada uma alíquota do extrato de 2 g da amostra dissolvida e homogeneizada em $10 \mathrm{ml}$ de água destilada no refratômetro, o qual indica o valor de sólidos solúveis totais em $\left({ }^{\circ}\right.$ Brix). 
$\mathrm{O} \mathrm{pH}$ foi determinado por medida direta nas amostras, utilizando um pHmetro digital (precisão $\pm 0,01 \mathrm{pH}$, MARCONI, PA 200) previamente calibrado com soluções-tampão de pH 4,0 e 7,0. Para determinar o $\mathrm{pH}$ foi utilizado um extrato a partir de $2 \mathrm{~g}$ de amostra dissolvidas em $10 \mathrm{~mL}$ de água destilada.

Para determinação da acidez total titulável (ATT) transferiu-se $10 \mathrm{~mL}$ do extrato da amostra de $10 \mathrm{~g}$ da polpa dissolvida em $100 \mathrm{~mL}$ de água destilada para um erlenmeyer, adicionando-se em seguida 3 gotas de solução de fenolftaleína a $1 \%$. A titulação foi feita com solução de $\mathrm{NaOH}$ até o aparecimento de coloração rósea.

A partir da equação 2: acidez $(\mathrm{g} / 100 \mathrm{~g})=\mathrm{n} * \mathrm{~N} * 64,02 /(\mathrm{p} * 10)$, determinou-se a acidez do extrato da polpa da semente do jatobá. Onde:

$\mathrm{N}$ = normalidade da solução de hidróxido de sódio;

$\mathrm{n}=$ volume da solução de hidróxido de sódio utilizada em $\mathrm{mL}$;

64,2 = Equivalente-grama do ácido cítrico.

$\mathrm{p}=$ massa da amostra em gramas.

\section{Resultados e Discussão}

A polpa farinácea do jatobá foi extraída do fruto jatobá, que se apresentava em forma de vagem e possui uma casca muito rígida. Diante dos resultados das análises das características físicoquímicas da polpa do fruto do jatobá obtivemos os seguintes dados apresentados na Tabela 1.

Tabela 1- Valores obtidos a partir das análises físico-químicas da polpa da semente do jatobá cultivado no agreste pernambucano. Fonte: Própria

\begin{tabular}{ll}
\hline \multicolumn{1}{c}{ Análise físico-química } & Valor medido \pm Desvio \\
\hline Umidade $(\%)$ & $22,60 \pm 2,5$ \\
Cinzas $(\%)$ & $2,44 \pm 0,045$ \\
ATT $(\mathrm{g} / 100 \mathrm{~g}$ de ác. cítrico) & $1,55 \pm 0,25$ \\
SST $\left({ }^{\circ}\right.$ Brix $)$ & $3,9 \pm 0,08$ \\
pH & $5,45 \pm 0,02$
\end{tabular}

De acordo com a Tabela 1, cada $2 \pm 0,013 \mathrm{~g}$ da polpa analisada tem 0,45 $\pm 0,053 \mathrm{~g}$ de água, ou seja, a polpa da semente do jatobá cultivado na agreste pernambucano apresenta $22,6 \pm 2,50 \%$ de umidade. Esse valor é maior do que o encontrado por Sousa et al. (2012) que verificaram a presença de $10,89 \%$ e em análises feita por Silva et al. (2001) o jatobá-do-cerrado apresentou teor de umidade na faixa de 11,97 a 12,94\% e o jatobá-do-mato apresentou teor de umidade na faixa de 12,44 a $13,42 \%$.

Na Tabela Brasileira de Composição de Alimentos (TACO, 2006), encontra-se o teor de 
umidade de diversas frutas, e entre as mais populares têm-se: abacate (83,8\%), abacaxi (86,3\%), banana prata $(71,9 \%)$, caju $(88,1 \%)$, laranja baía $(87,1 \%)$, e maça fuji $(84,3 \%)$. Assim, verifica-se que a polpa do fruto do jatobá apresenta teores de umidade considerados baixos em relação aos encontrados em outra fruteira, isso implica que o fruto do jatobá é adequado para elaboração de farinha e outros alimentos sólidos. Foi possível observar a cada $2 \pm 0,006 \mathrm{~g}$ de amostra 0,049 \pm $0,001 \mathrm{~g}$ de cinzas, ou seja a polpa apresentou um teor de cinzas de 2,44 $\pm 0,045 \%$.

A determinação de cinzas fornece uma indicação da riqueza da amostra em elementos minerais. Assim, a cinza de um material de origem tanto vegetal como animal é o ponto de partida para a análise de minerais específicos (MORETTO, 2008). As cinzas estão incluídas nas bases de dados como um dos componentes centesimais dos alimentos e observou-se uma variabilidade no teor de cinzas dos alimentos entre os dados publicados. Como os valores obtidos são menores que o valor obtido segundo Silva et al (1998) de 3,60\% de cinzas na farinha de jatobá na utilização de biscoito e o valor de 3,07\% de cinzas na farinha de jatobá-do-cerrado obtido por Martins (2006).

Estas variações podem ter sido decorrentes da complexa composição química dos alimentos, que sofre influência de fatores como espécie, manejo, plantio, processamento, entre outros. Essa diferença pode também está associada ao tempo de armazenamento e ao grau de maturação, visto que durante a maturação a polpa do jatobá tende a ficar mais seca.

De acordo com os dados apresentados na Tabela 1 foi encontrado o valor de $1,55 \pm 0,25$ g/100g para a ATT em ácido cítrico da polpa do jatobá, esse valor ficou muito próximo do valor encontrado por Sousa (2012) que foi de $1,11 \mathrm{~g} / 100 \mathrm{~g}$ de acidez em ácido cítrico na caracterização físico-química da polpa farinácea e semente do jatobá de mesmo fruto deste estudo e ficou inferior aos 2,76 g/100g encontrados por Cavalcante et al (2011) quando estudou a obtenção da farinha do fruto do Juazeiro e caracterização físico-química.

O teor de sólidos solúveis (Tabela 1) foi menor que o encontrado por Andrade et al (2008) na farinha da batata doce $\left(39,61^{\circ}\right.$ Brix) e por Aquino e Leão (2009) na farinha da acerola ( $40^{\circ}$ Brix). O teor de sólidos solúveis está relacionado à presença do teor de açúcares (COHEN e SANEN, 2010), quando processadas a adição de sacarose poderá ser menor.

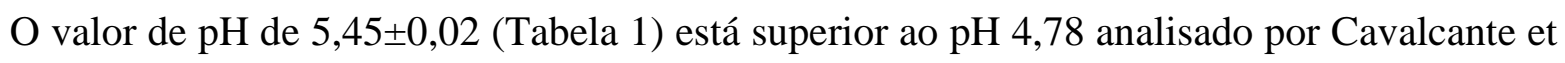
al (2011) quando estudaram a obtenção da farinha do fruto do e caracterização físico-química.

\section{Conclusões}

O clima e o manejo são determinantes à composição química dos alimentos, o que pode ter influenciado em algumas variações da caracterização físico-química do jatobá cultivado no agreste pernambucano, em Jucati-PE. Portanto, pode-se considerar a utilização da polpa da semente do 
jatobá na elaboração ou enriquecimento de outros alimentos a fim de elevar o valor nutricional e de maior aproveitamento das plantas da região, acrescentando a estes resultados mais análises químicas e sensoriais para um completo perfil da composição da polpa do jatobá.

\section{Referências}

ANDRADE, L. F. RABÊLO, W. C. A. C.; SILVA, G. S.; SANTOS, B. A. C.; MENDONÇA, S. L. R.; SANTOS, J. G. Estudo preliminar da influência da temperatura sobre a composição centesimal de farinha de batata-doce (Ipomoea batatas). Anais da $3^{\text {a }}$. Jornada Nacional da Agroindústria. Bananeiras, ago. 2008.

ANDRADE, M. B. Avaliação físico-química de frutos do cerrado in natura e processados para a elaboração de multimisturas. 2006. 85p. Programa de Mestrado em Ecologia e Produção Sustentável, Universidade Católica de Goiás, 2006.

AQUINO, A. C. M. S.; LEÃO, K. M. M. Obtenção e caracterização físico-química da farinha de resíduos do processamento de polpa de acerola. Anais do XVI Encontro Nacional e II Congresso Latino-americano de Analistas de Alimentos. Belo Horizonte, 2009.

CAVALCANTI, M. T; Obtenção da Farinha do Fruto do Juazeiro (Ziziphus joazeiro Mart.) e Caracterização Físico-Química. Revista Verde de Agroecologia e Desenvolvimento Sustentável. Grupo Verde de Agricultura Alternativa (GVAA) ISSN 1981-8203. 2011.

COHEN K. O.; SANEN, S. M. Parâmetros físico químicos dos frutos de mangabeira. Embrapa Cerrados, Planatina, DF, 2010.

Gouveia F. Indústria de alimentos: no caminho da inovação e de novos produtos. Inovação Uniemp. 2006 nov/dez.

GUARIM NETO, G. A. A importância da flora amazônica para uso medicinal. Horticultura Brasileira, Brasília, suplemento, v.15, 1997, p. 159-161.

BRASIL - Instituto Brasileiro de Geografia e Estatística (IBGE). Estudo Nacional de Despesa Familiar. 1999

INSTITUTO ADOLFO LUTZ. Métodos físico-químicos para análise de alimentos. 4. ed. São Paulo: Instituto Adolfo Lutz, 2008. 821-850.

MARTINS, B. A. Avaliação físico-química de frutos do cerrado in naura e processados para a elaboração de multimisturas. 2006. 61 f. Dissertação (Mestrado) - Universidade Católica de Goiás.

MATUDA GT, MARIA NETTO, F. Caracterização química parcial da semente de jatobá-docerrado. Ciênc Tecnol Aliment. 2005; 25:353-7

MELO, M. Da G.G \& MENDES, A. M. Da S. Jatobá Hymenaea courbaril L. Informativo Técnico Rede de Sementes da Amazônia No 9, 2005. Universidade do Estado do Amazonas. Manaus-AM, Brasil. 2005.

MORETTO, E. Introdução à ciência de alimentos. 2.ed. Ampliada e revisada. Florianópolis: Editora da UFSC, 2008. 
SANTOS, M.B.; CARDOSO, R.L.; FONSECA, A.A.O.; CONCEIÇÃO, M.N. Caracterização e qualidade de umbu-cajá. Revista Brasileira de Fruticultura. Jaboticabal-SP, v. 32, n 4.p114-125, 2010.

SILVA, J. DA; SILVA, E. S. DA; SILVA, P. S. L. Determinação da qualidade e do teor de sólidos solúveis nas diferentes partes do fruto da pinheira (Annona squamosa L.). Revista Brasileira de Fruticultura, v. 24, 2: p.562-564. 2002.

SILVA, R.G.V. Caracterização Físico-Quimica de Farinha de Batata-Doce Para Produtos de Panificação. Dissertação (Mestrado), Universidade Estadual do Sudoeste da Bahia, Bahia, Brasil, 2010.

SILVA, R. M.; SILVA, M. S.; MARTINS, K. A.; BORGES, S. Utilização tecnológica dos frutos de jatobá-do-cerrado e de jatobá-da-mata na elaboração de biscoitos fontes de fibra alimentar e isentos de açúcares. Ciência e Tecnologia de Alimentos, v. 21, n. 2, p. 176- 182 -2001.

SANTOS, L. A. S.; LIMA, A. M. P.; e PASSOS, I. V. 2001. Use and perceptions of alternative food in the state of Bahia: a preliminary study. Rev Nut. 14:35 - 40.

SOUSA, E. P.; SILVA, L. M. M.; SOUSA, F. C.; FERRAZ, R. R.; FAÇANHA, L. M. Caracterização Físico-Química da Polpa Farinácea e Semente do Jatobá. Revista Verde, v.7, n. 2, p. 117-121, 2012.

TACO. Tabela Brasileira de Composição de Alimentos. 2. ed. 113 p. 2006.

TEIXEIRA, M.L.F.; SANTOS, M.N. Atratividade da isca granulada de polpa de fruto do jatobá 